\title{
Designing and Evaluating Mathematical Learning by a Framework of Activities from History of Mathematics
}

\author{
Lenni Haapasalo, Harry Silfverberg and Bernd Zimmermann
}

Description of the Workshop: At first, on the basis of his long-term studies of the history of mathematics, BZ represented the eight sustainable activities that proved to lead frequently to new mathematical results at different times and in different cultures for more than 5000 years (Zimmermann 2003). After that, LH represented how this octagon may be used as an instrument to measure how the eight activities are supported within school mathematics, university mathematics, and the usage of ICT in everyday life, respectively. The results suggest that the support gained from all those areas is modest, and amazingly the support gained from the overall usage of ICT seems to have even a descending trend. The studies suggest that design of ICT-based learning environments orchestrated within the so-called pit-stop philosophy, promote a promising support for the Z-activities. This would mean a thorough shift in curriculum design, including dynamic assessment. HS represented a method for applying computer-aided analysis of the Finnish mathematics curriculum for the comprehensive school. Even though his computer-based datamining (Silfverberg, 2016) revealed that the curriculum expressions refer to many of the above-mentioned activities, they seem to be supported poorly in reality.

\footnotetext{
L. Haapasalo ( $\square)$

University of Eastern Finland, Joensuu, Finland

e-mail: lenni.haapasalo@uef.fi

(C) The Author(s) 2017 


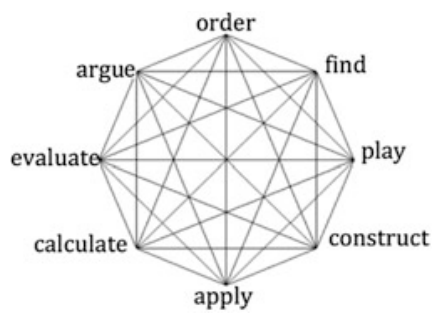

The Workshop activities included discussions about curricula in different countries and use of history of mathematics in mathematics instruction. There were participants from Africa, Asia, South-America, and Europe.

\section{References}

Haapasalo, L. (2007). Adapting mathematics education to the needs of ICT. The Electronic Journal of Mathematics and Technology, 1(1), 1-10. https://php.radford.edu/ ejmt/ deliveryBoy.php?paper=eJMT_v1n1p1

Haapasalo, L. (2008). Perspectives on instrumental orchestration and assessment-From challenges to opportunities. In Plenary speech in the 13th Asian technology conference in mathematics. (ATCM 2008). December 15-19, 2008, Bangkok, Thailand: Suan Sunandha Rajabhat University. Internet: http://atcm.mathandtech.org/EP2008/papers_invited/2412008_15968.pdf

Haapasalo, L. (2013). Adapting assessment to instrumental genesis. The International Journal for Technology in Mathematics Education, 20(3).

Haapasalo, L., \& Zimmermann, B. (2011). Redefining school as pit stop: It is the free time that counts. In W.-C. Yang, M. Majewski, T. de Avis, \& E. Karakirik (Eds.), Integration of technology into mathematics education: Past, present and future. Proceedings of the sixteenth Asian technology conference in mathematics (pp. 133-150). September 19-23, 2011. Bolu, Turkey.

Haapasalo, L., \& Zimmermann, B. (2015). Investigating mathematical beliefs by using a framework from the history of mathematics. In C. Bernack-Schüler, R. Erens, T. Leuders, \& A. Eichler (Eds.), Views and beliefs in mathematics education. Results of the 19th MAVI conference. Wiesbaden: Springer Spektrum.

Silfverberg, H. (2016). Using 'Zoctagon' as a frame for evaluating curricula. In L. Eronen \& B. Zimmermann (Eds.), Learning, technology, assessment. Festschrift in honour of Lenni Haapasalo (pp. 133-141). Münster, Germany: WTM Verlag für wissenschaftliche Texte und Medien.

Zimmermann, B. (2003). On the genesis of mathematics and mathematical thinking-A network of motives and activities drawn from the history of mathematics. In L. Haapasalo \& $\mathrm{K}$ Sormunen (Eds.), Towards meaningful mathematics and science education. Bulletins of the faculty of education (Vol. 86, pp. 29-47).

Open Access Except where otherwise noted, this chapter is licensed under a Creative Commons Attribution 4.0 International License. To view a copy of this license, visit http://creativecommons. org/licenses/by/4.0/.

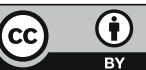

